\title{
In-canopy gas-phase chemistry during CABINEX 2009: Sensitivity of a 1D canopy model to vertical mixing and isoprene chemistry Supplement
}

\author{
Abstract. Synoptic-scale meteorological conditions for the \\ 4-5 August 2009 case period, time series of meteorology \\ used as input in CACHE, and modeled versus measured gly- \\ oxal.
}


A. M. Bryan et al.: Modeling in-canopy chemistry during CABINEX 2009

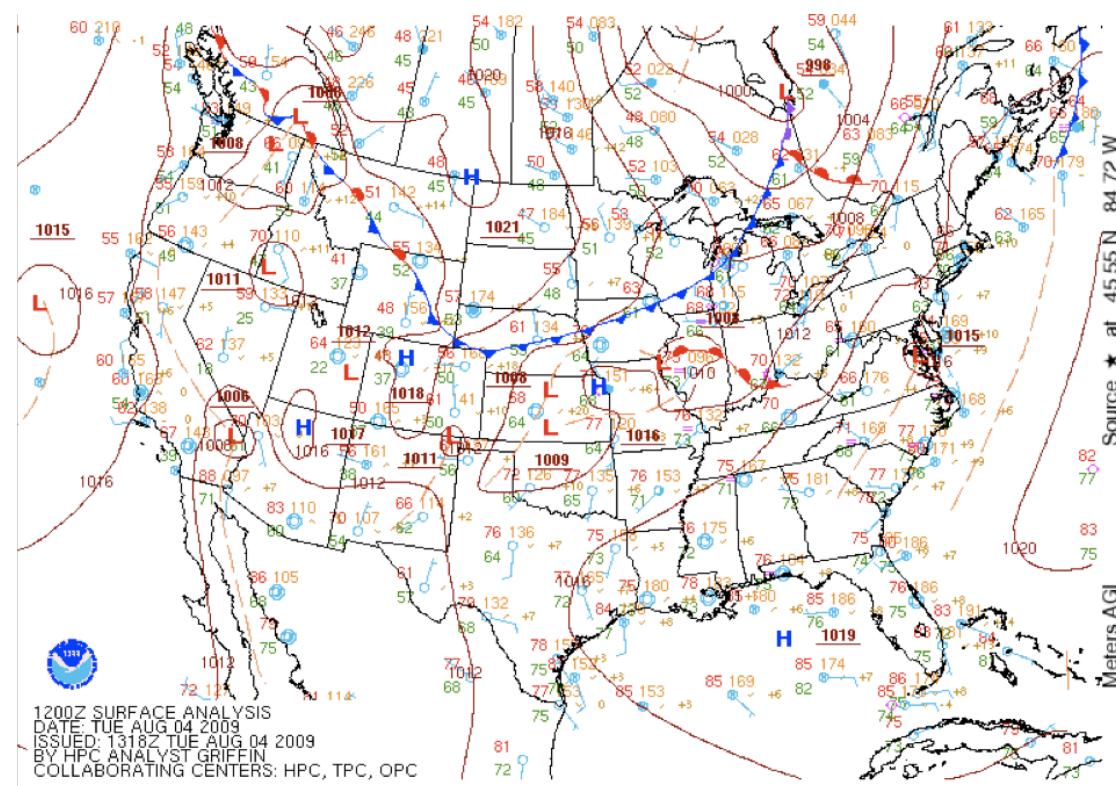

NOAA HYSPLIT MODEL Backward trajectories ending at 1800 UTC 04 Aug 09 EDAS Meteorological Data

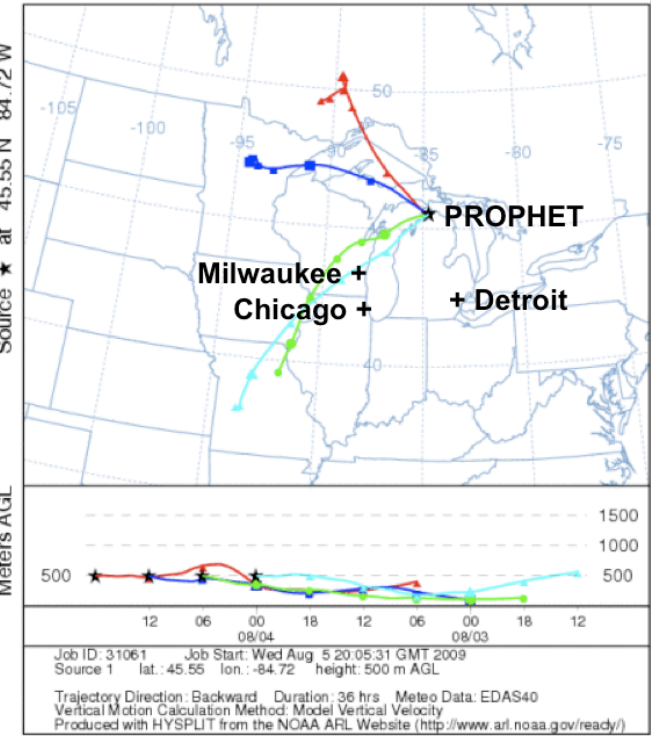

Fig. 1. Surface reanalysis (left) for 07 EST 4 August 2009 and 36-hour backward trajectories (right) ending at 19 EST on 3 August 2009 (cyan), and 01 EST (green), 07 EST (blue), and 13 EST (red) on 4 August 2009. Surface reanalysis data is provided by the National Center for Environmental Prediction (NCEP), a division of the NOAA Climate Diagnostics Center. Back-trajectory data is provided by the NOAA (R. R. Draxler and G. D. Rolph, HYSPLIT (Hybrid Single-Particle Lagrangian Integrated Trajectory) model, accessed via NOAA ARL READY Website, Air Resour. Lab., NOAA, Silver Spring, Md., 2003, available at http://www.arl.noaa.gov/ready/hysplit4.html) 


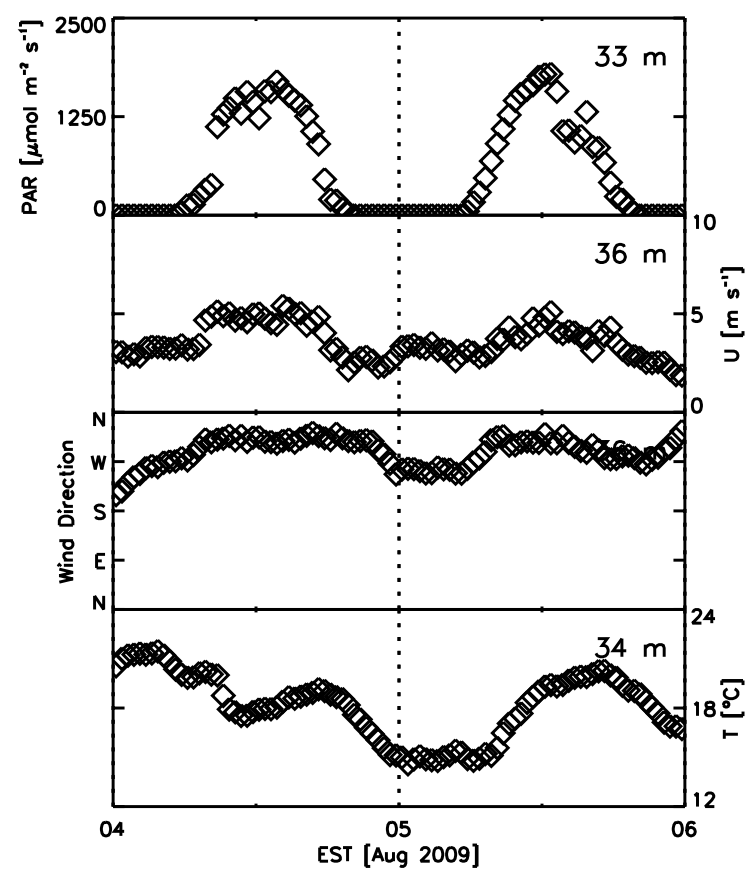

Fig. 2. Observed photosynthetically-active radiation (PAR), wind speed $(U)$, wind direction, and temperature $(T)$ measured at the PROPHET tower. 


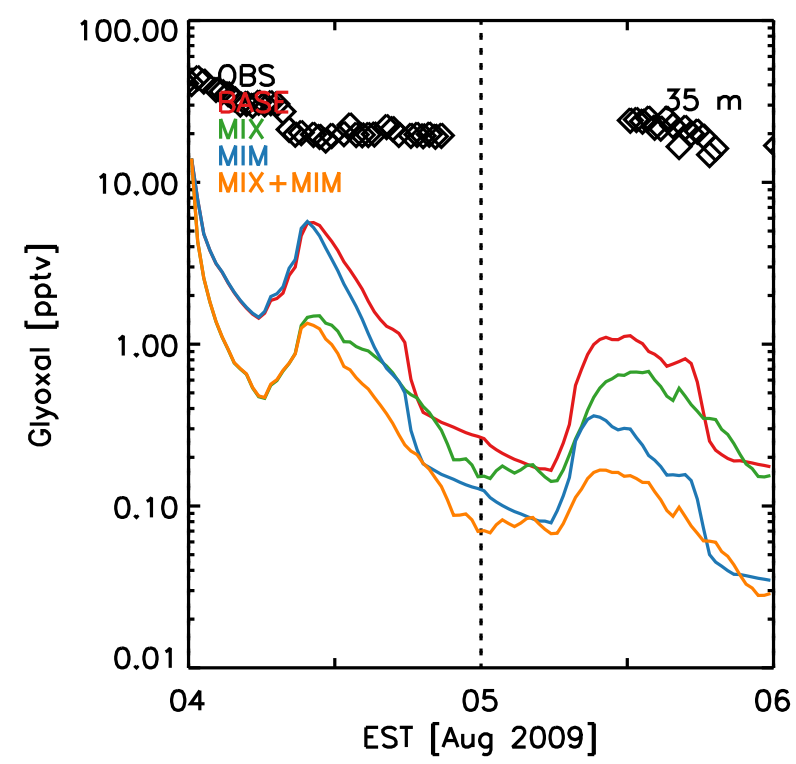

Fig. 3. Measured and modeled glyoxal concentrations during the 4-5 August 2009 simulation period. 